\title{
'Radar and the Rule of the Road'
}

\author{
Captain W. Burger and Captain A. G. Corbet
}

WE would like to reply to some of the comments and all the criticisms made on our suggested amendments and additions to the existing (1960) Regulations for Preventing Collisions at Sea, which have appeared in this Journal (20, $\left.103,34^{\circ}\right)$.

to Captain G. Swallow, R.N.

Upon reflection we agree to some extent with the comment on our suggested re-wording of section 16 (b). However, for the very reasons he has pointed out, with reference to certain court cases, we feel that the mariner must be made absolutely certain about his position in law with regard to this section. This section, as it stands, can be very misleading in that it gives the mariner in charge of a power-driven vessel the impression that he need not always stop his engines if he hears a fog signal forward of his beam from another vessel, which has not been sighted. Yet in all the court rulings that we have seen, concerning the interpretation of this section, there is not one case where a mariner has been excused from failing to stop his engines on the grounds of the 'apparent' escape clauses, i.e. because of ascertainment of position and/or practicability.

It seems to us, from studying these cases, that the only times a mariner might not be expected to stop his engines, or might be unwise to stop his engines, is either if he is in sight of the other vessel-in which case Rules 18 to 24 (incl.) might apply, or, if his engines are going astern. An alternative wording for section 16 (b) we suggest is:

' 16 (b). A power-driven vessel which hears a fog signal forward of the beam, from a vessel which is not in sight, shall stop her engines propelling ahead and then navigate with particular caution until danger of collision is over.'

We think that this wording would make it clear to the mariner that it is considered that stopping engines propelling ahead in these circumstances is as mandatory and as important as it is for a motorist to stop at a halt sign. We feel that the word 'particular' should be inserted because its omission implies that a mariner does not normally navigate with caution.

If section 16 (b) were to be amended to read as we suggest above, then section 3 of the Annex to the Rules would no longer be necessary.

Considering Captain Swallow's comments on our suggestions for section 16 (c):

We disagree with the view that it is the multilateral situation which is so frequently liable to be encountered and therefore should be the only realistic basis on which the Rules should be framed. If this were the case then Rules I 7 to 24 (incl.) would have to be eliminated because these strictly deal only with encounters between two vessels which are in sight of each other. When more than two ships become involved, and the degree of risk is the same for each, then the mariner has to act under Rules 27 to 29 . However, this situation is comparatively rare because often in a multilateral situation the degrees of risk of collision between own ship and the others sighted is not usually the sameone vessel is usually more dangerous than the others and, initially, the situation is regarded as a two-ship one, between own ship and the one presenting the 
greatest risk, and it is normally dealt with by Rules 17 to 24 (incl.). Upon passing this vessel safely the next most dangerous is dealt with and so on.

The principle of dealing with one vessel at a time in multi-lateral situations with vessels out of sight of one another, is just as sound as in multilateral situations when vessels are in sight of one another. In extreme multilateral situations such as those which can occur in the Dover Strait, off Ushant and off Cape Finisterre, we believe that the only real answer is a lane routing system. We hope that this will be proved by the Dover Strait experiment. Another point we should make here is that nearly all the so-called 'radar assisted' collisions have occurred in bilateral situations-no other vessels being involved other than the two which collided.

Turning now to the details of the proposed Rules that Captain Swallow has criticized.

We think it is necessary to insert 'by radar' to make it clear what form of detection is acceptable for the application of the sub-sections in 16 (c). Whilst we appreciate that there are instruments of detection other than radar, these instruments are non-existent on the vast majority of vessels, and the few vessels which do have them are likely to have radar as well, so we see no point in listing these alternative acceptable means of detection in the rules.

It is necessary to insert 'neither in sight nor heard' in sub-sections (i), (ii), (iv) and (v) of 16 (c) because if a vessel is heard forward of the beam then section 16 (b) would override section 16 (c) and if the vessel is sighted Rules 17 to 24 (incl.), Rule 4 and Rule 26, whichever applicable, would override the proposed sections 16 (b) and (c).

The reason why 'nor heard' is not inserted in sub-section (iii) is because it would be irrelevant-specific instructions for a vessel hearing another's fog signal apply only when this signal is heard forward of the beam ( 16 (b)). The reason why 'not in sight' is inserted in sub-section (iii) is because if the vessel is sighted Rule 24 would generally override 16 (c) (iii). Sighting or hearing the other vessel astern might indicate that Rule 4 is operative. The provisions in the proposed sub-section 16 (c) (iii) would generally be compatible with Rule 4 but, if not, Rule 27 would have to be invoked.

Regarding sub-sections 16 (c) (i) and (ii)-if own vessel is yawing, then we agree that a vessel which is detected right ahead while own ship is on course will be fine on the port bow when own ship yaws to starboard and fine on the starboard bow when own ship yaws to port. However, in this case, it does not matter whether one consults either sub-sections (i), (iv) and (v) or sub-sections (ii), (iv) and (v); the action advocated in each case is compatible. We certainly cannot agree that the present wording in section 6 of the Annex to the Rules is preferable-it is much too weak and loose.

In the comments on sub-section 16 (c) (i) it is asked, 'What does a vessel do when the circumstances of the case do not admit of an alteration to starboard?' We would think it obvious that one would take the best alternative action which would depend on the circumstances of the case-Rule 27 applies. Surely one could ask the same question of Rule 18-to which one would have to give the same reply.

Captain Swallow's other criticism of sub-section 16 (c) (i) is that it is unrealistic for it to include the expression 'to put the other vessel right astern'. First of all this is a mis-quote. The expression actually states 'to put the other vessel on the port side or right astern'. The sub-section does not suggest that 
own ship runs back to its port of departure any more than the present sections 16 (b) and (c) suggest that a power-driven vessel should leave her engines stopped. The option of putting the other vessel astern given in the proposed sub-section 16 (c) (i) is merely an initial step that can be taken by own ship to avoid collision. Thereafter, the rule specifies that the ship should then navigate with particular caution until danger of collision is over. In this case, i.e. the end-on meeting case, it can be a safer initial action to put the other vessel right astern than to simply stop own vessel and head her towards the threat.

Coming now to the comments on sub-section 16 (c) (iii). We agree that many hours may elapse in an overtaking case before risk of collision exists, the proposed sub-section (iii) does not suggest otherwise-the expression 'if there is risk of collision' is, in fact, included in the sub-section. Rule 24 is not 'admirable in this context'-it does not apply, the vessels are not in sight! Few mariners have not experienced the uneasiness of detecting an echo of an unseen vessel running them down from astern, and wondering whether or not this vessel has detected them and, if not, whether she will be able to hear own ship's fog signal in time to stop. The proposed sub-section (iii) prescribes the action that the mariner in this position should take to avoid collision and this action would support any action which may be taken either at the same time or later by the overtaking vessel either under sub-section 16 (c) (ii) or, perhaps later, under sub-section 16 (c) (v).

We cannot agree that sub-section 16 (c) (vi) is at variance with the preceding sub-sections. In fact Captain Swallow's earlier comments make it quite clear that he understands that 'sub-sections (i) to (v) are applicable to two-ship situations, while sub-section (vi) is applicable to multilateral situations'. Sub-section (vi) gives greater freedom of action which might be required for a multiship encounter.

\section{to Captain J. F. Kemp}

The first criticism made is that the proposed section 16 (c) is not compatible with the 'clear weather rules', i.e. the rules for vessels in sight of one another (the weather might not be 'clear'). This, of course, is desirable, as is said, to ensure an easy transition from one set of rules to the other. We believe that the proposed rules are, in fact, reasonably compatible. For example, the transition from 16 (c) (i) to 18 and vice versa would be simple enough for power-driven vessels; so would be the transition from 16 (c) (ii) and (iii) to 24 and vice versa.

We would agree that the two sets of rules are not perfectly compatible. For instance, in the case when two power-driven vessels are crossing so as to involve risk of collision, Rules 19, 21, 22 and 23 apply when they are in sight of each other; the proposed sub-sections 16 (c) (iv) and (v) could apply when they are out of sight and hearing. Thus, when they are in sight one is the give-way vessel and the other the stand-on vessel, and when they are out of sight and hearing, one or both of the vessels might change their velocities-depending on whether they have detected each other by radar or not. Should one or both vessels, initially out of sight of each other, be in the process of changing velocity, in accordance with Rule 16 , as they come into sight then Rules 19 and 21 cannot immediately apply because their wording implies that both vessels initially have constant or nearly constant velocities, which are leading them into collision, when they are in sight of each other. As Rules 22 and 23 are subordinate to 19 and 21 they would not apply at this moment either. In this event the mariners 
would have to do as they do nowadays, invoke Rules 27 and 29 , i.e. make their vessels assume velocities which are reasonably safe in the circumstances. As soon as the vessels have acquired steady velocities the situation would have to be assessed and collision avoidance taken, if necessary, in accordance with the appropriate rules for vessels in sight of each other.

Another case where the two sets of rules are not perfectly compatible is where, by the proposed sub-section 16 (c) (vii), a sailing vessel with radar (e.g. S.T.S. Sir Winston Churchill) might be taking action to keep out of the way of a power-driven vessel without radar. If they come into sight of each other then Rule 20 applies and the power-driven vessel should now take action to keep out of the way of the sailing vessel, which should now stand-on. This sudden shift of responsibility for giving-way and for standing-on from one ship to the other as they come into sight is, no doubt, a drawback but, generally, not a serious one because it has to be accepted that the initial actions prescribed in the proposed section 16 (c) would be taken in good time in accordance with section 5 of the Annex-and this is usually much earlier when vessels are out of sight of each other than when they are in sight, in otherwise similar circumstances. In other words, there should generally be ample time for transition even for the more difficult cases.

The second criticism is not justified. Radar observations can, in fact, be sufficiently accurate for the application of the proposed rules. This can be shown on a radar simulator. Undeniably, Masters and officers need proper training and experience in order to be able to make sufficiently accurate radar observations and to appreciate when their observations are unreliable. An untrained and inexperienced mariner can be as dangerous as an untrained and inexperienced motorist.

The third criticism is that the proposed rules are not simple enough. We accept that the answer to any problem should be as simple as possible but a complicated answer is better than either no answer or an inadequate simple answer. It is because we believe, as many others do, that the present regulations concerning action to be taken by vessels out of sight of each other are inadequate that we are striving for a better solution. During the last few years we have had many hours of intensive experience on a radar simulator-examining and discussing many types of maritime collision problems with scores of Masters and officers. The result is that we have changed our earlier opinion about the regulations. When they were first published we thought them to be adequatethey are certainly flexible and flexibility, we agree, is one of the most important features needed to cover the multitude of circumstances which can prevail in an encounter at sea. However, as a result of our experience we feel that the regulations are, in fact, unnecessarily flexible for many encounters, especially the strictly two-ship encounters. It is quite perturbing to see how often the actions taken by both ships cancel each other out-and both Masters acting within the law! In these cases the regulations are so flexible as to be virtually meaningless. Many mariners now wryly summarize the 'fog and radar' regulations up by saying, 'You can do what you like provided that you do it early, boldly and don't have a collision!' We are inclined to concur with them. It seems that if a mariner is involved in a collision, unless his ship is at anchor at the time, he will be blamed and humiliated in a court of inquiry no matter what else he has done to avert the collision. He can automatically be scapegoated under the present regulations. Of course, it is unlikely that the proposed regulations would change court 
attitudes, but they could help to reduce the number of collisions and subsequent court cases. We think that the proposed sub-sections in 16 (c) for twoship encounters are relatively simple. The mariner would just have to recognize that there was a risk of collision with the vessel he detects and then note its relative bearing, when his own ship is on course. If the echo is right ahead either sub-section (i) or sub-section (ii) would apply-depending on the rate of change of range in comparison with own ship's speed. If the echo is right astern then sub-section (iii) would apply; if to starboard-sub-section (iv) and if to portsub-section (v). The mariner would know that the action he takes in accordance with the appropriate sub-section would have a reasonable chance of success should the other vessel either have no radar or if it has radar and complies with the rules. At the same time there is sufficient flexibility in the proposed rules for him to have a reasonable chance of avoiding a vessel which is not obeying the rules, or which is being conducted in an unusual manner, or which is acting in the ignorance of the presence of his own vessel.

Dealing with his last point. The proposed section 16 (c) does not suggest that a mariner should present the port side of his vessel as a target for the other vessel to hit. Sub-sections (i), (iv) and (v) of 16 (c) all permit own ship to present her stern to the other vessel as an alternative to her port side. We think that all mariners in charge of vessels would take this seriously and realize that when they alter course to put the other vessel on the port side they would be expected to put it on a reasonably safe relative bearing on that side. The more threatening the other vessel, the greater the relative bearing would have to be until, in the most threatening case, the vessel is put right astern so that own vessel can run away or, at least, be ready to run away if the other vessel continues to run down towards her.

\section{to Commander P. C. H. Clissold, R.N.R.}

The summary of our proposed sub-sections (i) and (ii) into one paragraph largely satisfies us except in that it is less flexible than our (i) and (ii). We believe that this additional flexibility is essential. The reply we gave to Captain Swallow and Captain Kemp regarding the permitted alternative of putting the threatening vessel astern will, we hope, satisfy Commander Clissold on this point.

With regard to the suggested section (d) to be added to Rule 16 , we think it is over simplified and it certainly misconstrues the principles of our proposals. We have nowhere suggested that own ship shall not alter to port. In many cases it can be much safer and simpler to alter course to port to put the other vessel on a safe relative bearing, either on the port side or right astern, than to alter to starboard. Commander Clissold's suggested (d) also only deals with vessels approaching from forward of the beam. As we have said in our comments to Captain Swallow, mariners often have uneasy moments when a vessel, out of sight, is approaching them from abaft the beam. Although there is nothing in the present regulations which prevents a mariner from taking action in these circumstances, it is desirable that there should be regulations to ensure that what he does is consistent with what the vessel abaft the beam is likely to do if, in fact, it has, or does, detect own vessel either by radar, or by hearing, and complies with the regulations. 